\title{
English Language Teaching: Problems and Solutions
}

\author{
Dr. Jai Vardhan Kumar \\ Ph.D. \& NET Qualified \\ B.R.A. Bihar University \\ Muzaffarpur, Bihar, India \\ jaivardhankumar81@gmail.com
}

\begin{abstract}
English is one of the most influential and important language of the world. It is an international language. We cannot ignore the importance of English language because most of the learning and research are available in English medium. If we have to establish communication with the world, we must have to learn English. As English is a foreign language to us, there are lots of problems in teaching of English. Therefore, in this paper we will examine the problems of teaching of English as well as see if there is any solution to these problems.
\end{abstract}

Keywords: Link language, Aims of teaching, Text book, Aids.

English has acquired an international recognition. It has become a link language among the nations of the world. Similar is the case among the states of India because the people of south India have to take recourse of English as a medium of communication with their counterparts of the northern India. Since the Independence English is the unofficial official language of India. Without it we cannot imagine the existence of a nation because English is spread over the world. India is a developing country and the world cannot overlook the possibilities of Indian markets. To be aware of the happenings at the global level, to be immediately familiar with the scientific 
inventions and discoveries made abroad, it is essential for us to have the knowledge of English because it is the medium which provides us a chance to grab the opportunity of keeping pace to pace with our counterparts of the world. Not only this, if we want our erudition, our researches, our inventions, discoveries to be recognized at the world level then English language is the one and only medium.

Recognising the importance of English Mahatma Gandhi said in Young India:

"I do not want my house to be walled in on all sides and my windows to be stuffed. I want the cultures of all the lands to be blown about my house as freely as possible. I would have our young men and young women with literary tastes to learn as much of English and other world languages as they like and expect them to give the benefits of their learning to India and to the world" (Gandhi 170).

In view of the above, most of the schools run in India have English as the medium of instruction from primary to the higher secondary level. As English is a foreign language for Indians, so many problems and obstacles come in the way of teaching of English.

The following comment by Prof. V.K. Gokak sums up very aptly the deplorable condition of teaching English in India:

"The teaching of English in our schools is in a chaotic state today. Pupils are taught English for about six periods a week for six years. But it has been estimated that they hardly know 150 words by the time they join a university. This means that they have hardly been able to learn English words at the rate of one word per period. They do not know how to use the commonest structures of English.”(Balasubramanian 56)

Shortcomings/Problems: 
The conditions under which English is taught often differ from one place to the other. On the whole, the students of urban schools perform in a better way than those of rural schools. Likewise, the attainment of the student in public schools is better than that of their counterparts in ordinary schools. Some of the prevalent shortcomings of teaching English in India are given below for forming a clear conception of it:

\section{Lack of clear-cut policy-}

The place of English in the post-independence era has not been properly discussed and defined. It has been changing from time-to-time. In certain states it is no longer essential for a student to pass in English subject to get through the High school examination. The consequence is that the students are not serious about the study of English.

II. Little understanding of aims of teaching English-

Very few teachers understand the aims and objectives of teaching English language. Always a teacher is guided by the motive of enabling the students to get through the examination. For this, he makes them cram rather than to master the skills of the language. He is concerned and satisfied by only the passing percentage of the school, they are not even least concerned about the overall academic development of students.

III. Dearth of competent teachers-

All teachers of English aren't fully competent to do full justice to their assignment. The English Review Committee appointed by the UGC in 1965 under chairmanship of D.S. Kothari, remarked:

"There is a shortage of teachers. Those available have just passed the school final Examination, having themselves studied English in village school for 4 or 5 or 6 
years. They have little idea of correct pronunciation. Their vocabulary is limited as is their reading." (Report of the English Review Committee 12) (Web)

It is ironical to find that many teachers who did not offer English teaching in their training are assigned this subject. It is a misunderstood that any trained graduate teacher can teach English at higher secondary level so proficiently as compared to a specialized trained graduate teacher in English. A majority of teachers teaching English in schools at present are not aware of the new developments and research in the field of teaching of the language.

IV. Wrong Methods of Teaching-

Even today most of the teachers take recourse of translation method of teaching English which is regarded as wasteful activity for the purpose of teaching English. Consequently spoken English is neglected. Proper environment is not provided to the students to cultivate the habit of speaking in English. They cannot converse in English. They cannot form any language habits. A majority of teachers themselves are not familair with new techniques of teaching the language.

V. Defective textbook and curriculum-

Defective textbooks are still used in certain states. These books have not been systematically written and no attention is paid to the selection and gradation of language items in them. Such books have not adequate exercises for language practice. These books lack both the teacher's handbooks as well as workbooks for students. At college level also this problem is faced. Almost prescribed books are those ones which depict the western life and culture which are less appreciated by our students. There is a conceived notion that the quality of English would be enhanced by prescribing the difficult books. Students cannot attain the reading speed of texts which are incomprehensible to them and ultimately a sense of distaste for the subject is created within them. This unfortunate attitude is one among the obstacles which the school 
teacher must have to overcome. University syllabus doesn't fully satisfy this objectives of the teaching of English in India.

VI. Faulty system of examination-

The questions set for the examination generally aim at testing the cramming power of pupils . They fail to test the students' real ability in language skills. It is possible for students to get through the examinations just by memorising answers to certain set questions. One of the factors liable for the deterioration is, of course, the pattern of question-setting. It is very easy to predict what questions would be asked on what books during which examinations. The students simply have to learn those lessons by rote. The teacher also teaches only those aspects which are important for the specific examinations. Students and teachers are not given proper orientation and teachers are blamed for this. Students of English Honours are expected to be proficient in spoken English as well. They are unable to posses the facility to develop the power of written and oral expression during a classroom situation. Some marks should be reserved for internal assignments also, which is badly needed in today's evaluation system.

VII. Insufficient provision of Audio-visual aids-

Most of the schools and colleges function without the aids of audio-visual aids. As we see computer has become a part and parcel of our life, so it is expected to provide computers with all its related accessories to schools and colleges because it may prove very fruitful in teaching English as well as other subjects too. Most of the Indian teachers suffer themselves from pronunciation drawbacks therefore it would be in vain to expect from them to teach correct pronunciation skills to students. In this case computer may help a lot to teach pronunciation. There are so many websites which teach this skill. Main points of teaching may be presented through slide shows on the computers in Smart Class rooms. So these aids can't be overlooked as a means of teaching English in India. 
VIII. Over-crowded classes-

The classes in English are over-crowded. The proportion of students and teachers are found irrational. It becomes impossible for a teacher to pay attention to each student. A teacher can deliver lecture in this situation only when the students are passive listeners. It should even be recognized that the sensible add the teaching of English demands that the amount of scholars within the class be limited.

IX. Mother tongue interference-

In some ways mother tongue interferes in the learning and teaching of a foreign language. When a child learns his mother tongue there is no other language getting in his way. But as soon as he begins to learn a foreign language, the habits of mother tongue continually conflict with those of the foreign language. This conflict arises in all areas-sounds, structures, and vocabulary.

\section{Suggested Solutions:}

Some solutions to improve the standards and to overcome the difficulties in the way of teaching English are as follow:--

1. The policy regarding the place of English in our educational system should be well-defined and well guided. While framing such policy the national and international importance of English must be kept in mind.

2. The teacher must keep in his mind the aims of teaching English. There are--

(a) to enable the students to understand English when spoken,

(b) To enable them to write English,

(c) To enable them to speak English, and 
(d) To enable them to read English.

3. It is necessary for a teacher of English that they should have a sound command over the language so that they may able to converse with students in English. It will help in making the students' habit formation of speaking in English. They should talk to students on their problems, their activities, attitudes towards study and nation in a very simple and lucid style so that they may be encouraged to speak in English in response. English Speaking in Class and School Campus should be encouraged. Such environment is much needed to create the habit of expression in English.

4. UGC should play an active role in the conduct of Refresher courses for teachers at university levels and provide adequate funds to colleges and universities to organize these courses. Teachers should be provided with journals, current books to keep themselves updated in their specific fields. They should be encouraged to attend refresher course, to present their thoughts, experiences of teaching in journals, seminars etc. Such policy should be framed that would make teachers liable for the progress of the students.

5. There should be introduced standard books in the curriculum. The books by NCERT should be prescribed in all the schools. There should be prescribed standard books at college level also which may be helpful in building the literary and professional value of English language.

6. There is a need to change the pattern of the examination. The questions should be properly framed to test the mastery of the language skills. Cramming should be discouraged. There is also a need for the oral tests to see whether the students have acquired the skills for interaction.

7. Some competitions like Storytelling, Speech, Reading competitions, poetry recitation etc. should be held at regular interval and every student should be encouraged and prepared for participation in such events. It will break their hesitations in speaking English before a huge crowd and help to develop their speaking ability as well as personality development. 
8. There are many methods of teaching English. But we must follow a complete method keeping in view the objectives of teaching English. This method must be one which helps to develop the four skills mentioned above. Says Wyatt and Thompson:

"no type of work should be sacrificed to any other and skill in each must be developed to the fullest extent possible for the stage reached in the course of instruction.”(Jain 173)

It is the objective which will determine the method.

9. Necessary audio-visual aids should be provided to schools/colleges. The teacher is expected to know to prepare the inexpensive aids. He must know how to use these aids specially computer, slide show, tape-recorder, films etc. Smart Classes should be made mandatory for every school including government ones.

10. There should be a certain ratio of students per teacher. Otherwise it affects the quality of education. Government should take necessary step in this direction and should prepare a clearcut policy making it mandatory for all institutions from primary to higher level.

11. The teacher should reduce the use of mother tongue to the minimum in the classroom so that the students get more practice in listening English.

Conclusion:

Teaching of English in India is not as difficult as we take for. The necessity is that we should handle it with proper care taking into considerations all the problems-whether it be small or a big one, and finding a suitable solution for it using our all intelligence and ability. Because for a teacher, "His class room is his laboratory. Just as a scientist is free to work in his laboratory, so is a teacher to feel himself free. At the same time, he should be alert, like the scientist, 'to invent' new methods, new devices, which may lead him to towering success" (Jain 176). 


\section{References}

Gandhi , Mahatma. Young India. June 1, 1921, p. 170

Jain, R.K. Essentials of English Language Teaching. Agra. Vinod Pustak Mandir, 1985.

Balasubramanian T., Teaching of English Made Easy. Madras. Macmillan India Limited, 1985.

Report of the English Review Committee (Online): 12. Web. Accessed on 30 August, 2020.

URL-

14.139.60.153/bitstream/123456789/6862/1/REPORT\%20OF\%20THE\%20ENGLISH\% 20REVIEW\%20COMMITTEE-CSL-IOD_IO27403.pdf 